\title{
Knowledge of Reproductive Health Issues among the Students of P. N. Campus Pokhara
}

Amin Palikhe and Akhila Shrestha

The article entitled "Knowledge of Reproductive Health Issues among the Students of P. N. Campus, Pokhara" has studied to get the knowledge about the reproductive health issues. Reproductive health is one of the important factors of population studies. Several studies have been made concerning the reproductive health issues but there are few research works on the knowledge of reproductive health, especially, in $P$. N. Campus. The present study attempts to find out knowledge of reproductive health issues among the students in the $P$. N. Campus. This study was based on the primary information collected from the field survey in P.N. Campus. The sample used for collection of data is random sampling. Basically, both descriptive and analytic research design and simple statistical tools like frequency table, and cross tabulation have been used here. To test the hypothesis, Chi- Square test with contingency table has been presented. Among the total 116 students, 58 percent female and 42 percent male were taken for sample. The median age for the sample population was 23 years. About 31 percent among them were married. This research finds out the knowledge of reproductive health issues like media of knowledge, sources, reproductive health issues areas and level of knowledge among the selected demographic background of respondents.

Key Words: Chi-Square, Issues, Knowledge, Reproductive Health, Subject Matters,

\section{Introduction}

Reproductive health is relatively a new concept emerged after 90s that comprehensively addresses all of the health issues regarding reproductive health for both women and men, irrespective of their age. Reproductive health sometimes addresses women's health issue as a whole, since most of them are closely related to Reproductive Health. Good health is one of the basic human rights endorsed by various international initiative as well as prerequisite of socioeconomic development. In many countries and cultures women are not allowed to participate fully in the decision making process that directly affects their health status. Because women play major roles in raising children and caring for family members. Death and illness among women affect health and wellbeing of the family as a whole and consequently the entire population. Reproductive health is one of the aspects affecting the health of an individual. For the first time, the concept of reproductive health was formally brought into existence from the international conference on Population and Development held at Cairo in 1994 A. D. The term reproductive health refers to the process of giving birth. In this sense, reproductive health means the study of factors that affect the health of a person for reason of reproduction (Paneru, 2007).

International Conference on Population and Development, the first global issue to discuss, debate and reach a consensus on this issue has defined reproductive health [RH] as "A state of complete physical, mental and social well-being and not merely the absence of disease or infirmity in all matters relating to reproductive system and its functions and process"(UN, 1994). Hence reproductive health implies that people are able to have a satisfying and safe sex life and that they have the capability to reproduce and have the freedom to decide if, when and how often to do so. RH also includes sexual health, the purpose of which is enhancement of life and personal relation and not merely the counseling and care related to 
Janapriya Journal of Interdisciplinary Studies, Vol. III (December 2014)

reproduction and sexual transmitted disease. It is recognized that RH is a crucial part of overall health in infant, childhood and adolescence; it also sets the stage for health beyond the reproductive years for both men and women and has pronounced effects from one generation to another (MOH, 1998).

The UN system and the international community believe that RH includes family planning, safe maternal mortality and protection from the transmission of STDs including HIV/AIDS and from violence and sexual abuse should be available in all situations and circumstances based on the needs and repressed demands of refugees. In this respect, priority is given to the needs of women adolescent girls.RH is important for men, women and children. The reproductive system, in function, dysfunction and disease, plays a central role in women's health. This is different from the case with men and women. A major burden of the disease in female is related to their reproductive function and reproductive system, and the way society treats or mistreats them because of their gender. Reproductive health is a stable in which people have the ability to reproduce and regulate their fertility; women are able to go through pregnancy and childbirth sagely. Among essential components of RH can include family planning, maternal health, preventing abortion and managing the complications of unsafe abortion, preventing and treating STDs including HIV/AIDS and eliminating traditional practice like female genital mutilations that harms women's RH ad well-being (UNFPA,2001)

Reproductive health implies that, apart from the absence of disease or infirmity, people have the ability to reproduce, to regulate their fertility and to practice and enjoy sexual relationships. It further implies that reproduction is carried to a successful outcome through infant and child survival, growth and healthy development. It finally implies that women can go safely through pregnancy and childbirth, that fertility regulation can be achieved without health hazards and that people are safe in having sex (Fathalla, 1988)

The various elements of RH are strongly interrelated and improvement of one can facilitate the improvement of others, while all elements of RH are individually important, given the current socio economic and environmental condition in the world particularly in developing countries, fertility regulation is central to all other aspects of reproductive health (WHO, 1992).

The burden of a RH disease is primarily a function of its prevalence and its seriousness to the individual concerned. In the case of reproductive health, the impact is not limited to the individual directly concerned. Inability of individuals and couples in developing countries to regulate and control their fertility because of lack of information and inadequacy of services, is not only affecting the health of the people immediately concerned and their families, but has implications for their societies and their countries, for global stability and for the balance between population and natural resources and between the human species and the environment.

Communicable diseases are important because they can affect other people too. Of all communicable diseases, STDs including HIV infection, are least amenable to control. Even attempting to erect national barriers will not stop them. People with other communicable diseases are less likely to travel than people with STDs, which are sometimes described as "air-borne" diseases, to indicate the importance of air travel in their trans-national spread.

To know the knowledge on RH issues, P. N. Campus, Pokhara is chosen as the specific area for this study. Pokhara is one of the old urban sectors situated in Western Nepal, Kaski District and Gandaki Zone. All types of facilities are available in Pokhara so that many people migrated from other districts of this region and other parts of the country. Prithvi Narayan Campus is situated in the Northern part of Pokhara. The campus has an area of approximately 515 ropani stretched from East to West. There is no doubt that it is the second largest campus in the country where programs of Humanities, Education,
Science, Management and Law are run.

Reproductive behavior has become an emerging worldwide concern in most of the countries. RH is relatively a new concept that comprehensively addresses all of the health issue regarding reproductive for both women and men, whether young or old. Among the major reproductive and sexual health hazards that young people face are: STDs, unwanted pregnancies, including illegal abortion related complications, higher risks of maternal and infant morbidity and mortality, low birth weight and pre-maturity among the children of very young mothers. The knowledge of reproductive health is needed for adolescents since they are likely to expose in the reproduction. Therefore, reproductive health knowledge must provide to all adolescents for their healthy life. Reproductive health services and information should be accessible and affordable for all adolescents. This study focuses on the knowledge of subject of reproductive health issues among the students of the P. N. Campus, Pokhara.

\section{Data and Method}

The sample design is purposive sample design, which is especially targeted to management, humanities and social science, education and science and math faculties. Total numbers of students have been divided into these stratified groups. The proposed research has been descriptive in nature. The proposed research has been descriptive when it has to explain the knowledge of reproductive health situation of students. The research was primarily based on primary data. However for the support, secondary data has been also used. Total number of students has been divided into these stratified groups. Random sampling has been used for this research. 116 students are taken for the sample. The questionnaires were used for the collection of primary data and their natures were structured with both open and closed ends. The questionnaires were given to the students of P. N. Campus. Necessary primary data were collected through sample survey. The questionnaires were directly administered and distributed to the sampled students and the respondents were intimately supervised during the filling of the questionnaire. The processing of the study results began soon after the start of the fieldwork. The raw data collected in the field survey were carefully checked to minimize the probable errors and data were postcoded if necessary. Then, collected data were processed in Statistical Package for Social Science (SPSS) and the computed data were used to generate tables and statistics to translate the number into meaningful results. The frequency distribution tables have been used to analyze the data. Descriptive as well as analytical measures were followed. The data collected and processed have been analyzed using various tools such as percentage, chart, weighted mean, chi -square test, etc. The ethical consideration is also taken from the respondents.

\section{Results and Discussion}

The various elements of $\mathrm{RH}$ are strongly interrelated and improvement of one can facilitate the improvement of others, while all elements of $\mathrm{RH}$ are individually important, given the current socio economic and environmental condition in the world particularly in developing countries. Fertility regulation is central to all other aspects of reproductive health. Therefore, this research work is tried to know the knowledge of reproductive health matters from the students. Due to the lack of proper knowledge, many adolescents have been victims of sexual diseases, sexual coerce and violence, unwanted sex and pregnancy, and unsafe abortion which can be removed by providing knowledge on reproductive and sexual health.

Table 1 shows the percent of students from P. N. Campus classified according to the selected background characteristics. A description of the background characteristics of the 116 students age 15- 
49. Regarding age mix, 43.1 percent are taken from the age group 20-24 followed by 15-19 and so on. The place of residence is another characteristic that determines access to service and exposure to information pertaining to RH and other aspect of life. The majority of respondents reside in V.D.C. with $66.4 \%$ of respondents and $33.6 \%$ reside in municipality. Education is one of the most influential factors affecting an individual's attitude, knowledge and behavior in various facets of life. A total of 116 students were enumerated. Among them, 42 percent students were male and 58 percent female. Among 116 students of age 16 to 40 plus, the majority of unmarried students were 69 percent whereas 31 percent students were married. Some 87.1 percent respondents are related to single family and the rest is related to joint family. . Among the faculties, education, management and humanity are taken more than other students. That is indicated by $45.7 \%$ and $25.9 \%$ for education and management followed by humanities and social science respectively. Ethnicity of students of P. N. campus students were more Brahman/Chhetry (56\%) followed by Janjati and limited number was covered by other caste in the campus. There were maximum numbers of respondents related with Brahman/Chhetry. So those samplers obviously were more concerned with the Hindu origin whereas Janajati was related with Buddhist origin, i.e 13.8\%. 95.7 percent respondents use Nepali as mother tongue. 66.4 percent students have no job or regular income. Among the respondents only 33.6 percent respondents responded the questions about the level of family income. Among the 33.6 percent, 43.6 percent falls in the group of less than ten thousand whereas 17.9 percent falls in the group of more than ten thousands group. Among the responded respondents, 30.8 percent told "Do not Say".

\section{Table 1: Percent of Respondents Classified According to Selected Background Characteristics}

\begin{tabular}{lclc}
\hline Characteristic & Percent (\%) & Characteristic & Percent (\%) \\
\hline Age & & Religion & \\
$15-19$ & $31(26.7)$ & Hindu & $98(84.5)$ \\
$20-24$ & $50(43.1)$ & Buddhist & $16(13.80$ \\
$25-29$ & $23(19.8)$ & Kirati & $1(0.9)$ \\
30 and above & $12(10.4)$ & Others & $1(0.9)$ \\
Education $\dagger$ & & Mother Tongue & \\
PCL(11-12) & $31(26.7)$ & Nepali & $111(95.7)$ \\
Bachelor(13-15) & $51(44.0)$ & Others & $5(4.3)$ \\
Degree(16-17) & $34(29.3)$ & Faculty & $30(25.9)$ \\
Sex & & Management & $9(7.8)$ \\
Male & $49(42)$ & Science and Math & $24(20.7)$ \\
Female & $67(58)$ & Humanities and Social & Science \\
Marital status & & Education & $53(45.7)$ \\
Unmarried & $80(69)$ & Income & $39(33.6)$ \\
Married & $32(31)$ & Yes & $77(66.4)$ \\
Family Size & No & $17(43.6)$ \\
joint & $15(12.9)$ & $0-9999$ & $7(17.9)$ \\
Single & $101(87.1)$ & 10000-19999 & $3(7.7)$ \\
Ethnicity/Caste & 20000 and above & $12(30.8)$. \\
Brahman/Chhetry & $65(56.0)$ & Do not Say & $48(41.4)$ \\
Hill/Janajati & $43(37.1)$ & Place of Residence & $68(58.6)$ \\
Tarai Origin & $3(2.6)$ & Kaski & \\
Dalits & $4(3.4)$ & Outside Kaski & $39(33.6)$ \\
Others & $1(0.9)$ & Birth Place & $77(66.4)$ \\
& & Urban & \\
\hline & Rural & \\
\hline \hline
\end{tabular}

The knowledge about the RH is surveyed. Respondents have been asked various questions about the knowledge of RH and its components. These types of indication clearly indemnify the knowledge about $\mathrm{RH}$ issues.

Table 2: Percentage of Respondents Who Receive Information about Reproductive Health Issues According to Sources

\begin{tabular}{lc}
\hline Source of Information of RH & Total \\
\cline { 2 - 2 } Mon and Daddy & Response (\%) \\
Family Member & $8(6.9)$ \\
Friend & $4(3.4)$ \\
Teacher & $30(25.9)$ \\
Boy and Girl Friend & $29(25.0)$ \\
Doctors & $9(7.8)$ \\
Counselor & $26(22.4)$ \\
Books & $15(12.9)$ \\
Cinema and TV & $60(51.7)$ \\
Radio & $32(27.6)$ \\
Newspaper & $41(35.3)$ \\
Clubs & $38(32.8)$ \\
Professional Sexiest & $12(10.3)$ \\
\hline
\end{tabular}

Where, table 2 shows the information of RH among the respondents. Among them the majority respondents receive the information from friends, teachers, counselors, doctors, books, cinema, radio, newspapers etc. But they rarely take it from sex professionals. Respondents take RH issues from the books followed by others like radio, newspaper, cinema, friends, teachers, doctor etc.

Table 3: Percentage of Respondents Who Deliver the Reproductive Health Issues by Different Media

\begin{tabular}{lc}
\hline Medium of Information about Reproductive Health: & Total \\
\cline { 2 - 2 } & Yes Response (\%) \\
\hline Newspaper & $103(88.8)$ \\
Radio & $109(94.0)$ \\
Television & $107(92.2)$ \\
Cinema & $97(83.6)$ \\
Family Member & $93(80.2)$ \\
Teachers & $106(91.4)$ \\
Friend and Club & $97(83.6)$ \\
Public Vela & $77(66.4)$ \\
Mother Group & $85(73.3)$ \\
Health Post & $111(95.7)$ \\
VDC and Municipality & $55(47.4)$ \\
\hline
\end{tabular}

Table 3 shows the way of providing the information about RH to people. Among the respondents more than eighty percent were more like to provide information from Newspaper, Radio, Television, Cinema, 
Friend, Health post but VDC and Municipality is not the best way to provide the information of RH issues.

Table 4: Percentage of Knowledge Who Know the Different Issues of Reproductive Health Total

Reproductive Health Concern Group:

Family Planning

Safely Motherhood

Orphan Child Care

Divorce Law

Safely Abortion

Care of Older People

Sexual Diseases and HIV

95(81.9)

$70(60.3)$

$11(9.5)$

$14(12.1)$
$105(90.5)$

$105(90.5)$
$8(6.9)$

$81(69.8)$

Mortality Rate

$39(33.6)$

Stage of Adolescence

Birth Rate

Age of Marriage

$78(67.2)$

$50(43.1)$

$58(50.0)$

Communication Media

$45(38.8)$

Table No 4 reveals that the majority of the respondents responded the areas of reproductive health issues. They have no doubts about the areas of RH issues. Because most of the respondents said that reproductive health is concerned with all the factors except child care, older people and divorce. It means that most of the respondents have knowledge about the areas of RH but they have no clear knowledge about the communication media whether it falls under the area or not.

Table No 5 shows knowledge of RH issues among the selected background characteristics. Table 5 includes the demographic factors with analysis of Chi-Square. Under the chi-square test, significance level of $1 *$ percent, $5 * *$ percent, $10^{* * *}$ percent level has been tested. Family size, mother tongue and birth place do not make any significant difference between the knowledge of RH issues. Education, sex, ethnicity, religion, faculty and regular income has 5 percent significant difference about issues of RH and background characters. Whereas age mix and place of residence of background characters has highly significant difference of RH issues.

Table 5: Percentage of Respondents Who have Knowledge about Reproductive Health Issues According to Selected Background Characteristics

\begin{tabular}{|c|c|c|c|c|}
\hline \multirow{2}{*}{ Characteristic } & \multicolumn{4}{|c|}{ Knowledge of Reproductive Health Subject Matters } \\
\hline & More (\%) & General (\%) & No $(\%)$ & Test \\
\hline Age & & & & $10.049^{* * *}$ \\
\hline $15-19$ & $4(16.7)$ & $27(31.4)$ & & \\
\hline $20-24$ & $10(41.7)$ & $35(40.7)$ & $5(83.3)$ & \\
\hline $25-29$ & $7(29.2)$ & $15(17.4)$ & $1(16.7)$ & \\
\hline 30 and above & $3(12.4)$ & $9(10.7)$ & & \\
\hline Education $\uparrow$ & & & & $6.442 * *$ \\
\hline $\operatorname{PCL}(11-12)$ & $2(8.3)$ & $27(31.4)$ & $2(33.4)$ & \\
\hline Bachelor(13-15) & $13(54.2)$ & $36(41.9)$ & $2(33.3)$ & \\
\hline Degree(16-17) & $9(37.5)$ & 23(26.7) & $2(33.3)$ & \\
\hline Sex & & & & $7.2^{* *}$ \\
\hline Male & $12(50)$ & $37(43)$ & & \\
\hline Female & $12(50)$ & $47(57)$ & $6(100)$ & \\
\hline
\end{tabular}

Family Size

joint

Single

thnicity/Caste

Brahman/Chhetry

Hill/Janajati

Tarai Origin

Dalits

Others

Others

Religion

Hindu

Buddhist

Kirati

Mother Tongue

Mothe

Nepali

Others

Faculty

Management

Science and Math

Humanities and

Social Science

Education

Regular Income

Yes

Place of Residence

Kaski

Outside Kaski

Birth Place

Urban

Rural

\begin{tabular}{|c|c|c|c|}
\hline & & & $1.428^{*}$ \\
\hline $3(12.5)$ & 11(12.8) & $1(16.7)$ & \\
\hline $21(87.5)$ & $75(87.2)$ & $5(83.3)$ & \\
\hline $16(66.7)$ & $46(53.5)$ & $3(50)$ & \\
\hline $8(33.3)$ & $33(38.4)$ & $2(33.3)$ & \\
\hline 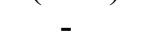 & $2(2.3)$ & $1(16.7)$ & \\
\hline- & $4(4.7)$ & - & \\
\hline - & $1(1.2)$ & - & \\
\hline $22(91.7)$ & $70(81.4)$ & $6(100)$ & $4.22 * *$ \\
\hline $2(8.3)$ & $14(16.3)$ & - & \\
\hline - & $1(1.2)$ & - & \\
\hline - & $1(1.2)$ & - & \\
\hline $23(95.8)$ & $82(953)$ & $6(100)$ & $0.5548^{*}$ \\
\hline $1(4.4)$ & $4(4.7)$ & - & \\
\hline $6(25)$ & $22(25.6)$ & $2(33.3)$ & $7.081 * *$ \\
\hline $1(4.2)$ & $6(7)$ & $2(33.3)$ & \\
\hline $7(29.2)$ & $17(19.8)$ & & \\
\hline $10(41.7)$ & $41(47.7)$ & $2(33.4)$ & \\
\hline $13(54.2)$ & $25(29.1)$ & $1(16.7)$ & $5.94 * *$ \\
\hline $11(45.8)$ & $61(70.9)$ & $5(83.3)$ & \\
\hline & & & $18.06^{* * *}$ \\
\hline $12(50)$ & $34(39.5)$ & $2(33.3)$ & \\
\hline $12(50)$ & $52(60.5)$ & $4(66.7)$ & $001 *$ \\
\hline $8(33.3)$ & $29(33.7)$ & $2(33.3)$ & \\
\hline $16(66.7)$ & $57(66.3)$ & $4(66.7)$ & \\
\hline
\end{tabular}

Table 5 shows the knowledge of reproductive health issues and selected backgrounds of the respondents. Regarding the age mix, age group 20-24 has more and average knowledge of RH but 15-19 age group has no more knowledge. Bachelor and degree level students have more knowledge of RH whereas 33.33 percent from all level of education has no knowledge of RH. Female has more knowledge of RH in comparison to male respondents. Single family has either more knowledge or no knowledge at all. Brahman/Chhetry has more knowledge followed by Janajati and Dalits. Hindu has more knowledge regarding $\mathrm{RH}$. Respondent of Nepali mother tongue has more knowledge than non-speaking Nepali tongue.

\section{Conclusion}

It is found from the survey that the majority of students are from Kaski district followed by surrounding districts. Similarly, majority of students are from the VDCs where their caste/ethnicity was Brahmin/Chetry followed by Janajati. There is an urgent need to create awareness and change the attitude of family members in the communities towards the subject of RH. RH care is the constellation of methods, techniques and services. All these factors contribute to reproductive health and well-being by 
preventing and solving reproductive problem. Regarding the knowledge of RH issues, the students are in average. They have thought that RH knowledge should be talked freely but also some of the students do not like to talk about RH issues with other persons. They are receiving the information of RH from cinema, news, books, and friends rather than others but also told that above mentioned way would be better to get the knowledge of RH issues. Most of the respondents have knowledge about RH issues.

\section{Acknowledgement}

This research work could never have been completed without the invaluable co-operation and assistance of Mr. Bidhan Acharya, Associate Professor, Central Department of Population Studies, TU, Prof. Dr. Vikash Kumar KC, Head of Department of Statistics, Mr. Rameshor Baral, Teaching Assistance of Population Studies, P. N. Campus, and Mr. Rajendra Paudel, Lecturer of English, Administration Department of P. N. Campus. I would also like to express my deep sense of gratitude towards my friend Ms. Niru Maharjan and towards my entire colleagues for their assistance.

\section{References}

Acharya, B. P. (2007). "Ageing and Reproductive Health of Elderly Women", Central Department of Population Studies, Kirtipur, Population Magazine, Vol.-V

Arambepola, C and Rajapaksa, L. C. (2014). "Decision making on unsafe abortions in Sri Lanka: a casecontrol study", Reproductive Health 2014, December 2014

CDPS, (1996). "Migration, Education, Birth, Death and Contraceptive Survey", CDPS, TU, Kathmandu, Nepal

Fathalla M.F. (1988). Research needs in human reproduction In: Research in Human Reproduction: Biennial Report (1986-1987). Edited by E. Diczfalusy, P.D. Griffin \& J. Khanna. World Health Organization, Geneva. p.341

MoH/HMG. (1998).Safe Motherhood Policy, Nepal

MoH/HMG. (2004).National Neonatal Strategy, Nepal

MOPE. (2005). Report on ICPD at Ten, Nepal

MoH/HMG. (2006).National HIV/AIDS Strategy, Kathmandu, Nepal

MoH/HMG. (2060).National Policy on Safe Abortion, Nepal

Newman, K., F., Mayhew, S. h. and Stephenson, J. (2014). Population, sexual and reproductive health, rights and sustainable development: forging a common agenda, Reproductive Health Matters, May 2014, Vol. 22, Issues 43

Paneru, I. P. (2007). Reproductive Health. Central Department of Population Studies, Kirtipur, Population Studies Society of Nepal, Population Magazine, Vol. - V

UN, (1994). International Conference on Population and Development": Plan of Action, New Work, America, p 30-37

UNFPA, (2001). The State of World Population, UNFPA, New York, USA, (2007:49:58).

WHO. (1992). Reproductive Health: A Key to Brither Future in Biennial Report, Geneva, Switzerland, p 30-39

\section{Caste: A Socio-political Institution in Hindu Society}

Bhanubhakta Sharma Kadel

Abstract: Caste has been a form of social stratification characterized by endogamy, hereditary transmission of a lifestyle, which often includes an occupation, ritual status in a hierarchy and customary social interaction and exclusion based on cultural notions of purity and pollution. Hierarchy, commensality, repulsion and hereditary membership and specialization are the major characteristics of caste system. It is assumed that castes arose from differences in family ritual practices, racial distinctions, and occupational differentiation and specialization but it is socio-political institution mainly characterized by domination and subjugation. APA model has been applied to this research work. The theory of origin of caste and its orientation has been of great use in preparing the article. The readers will be aware of the implicit intention of the writer that the caste system that pervades the South Asian region is not the product of religio-cultural institution nor it has any relation with the Brahminical scripture like the Vedas but it has socio-political orientation.

Key Words: caste, cultural, ritualistic, social, economic, political, hierarchy

\section{Introduction}

In general, as Encyclopedia Britannica defines, caste is an endogamous hereditary group of families, bearing a common name; often claiming a common descent; as a rule professing to follow the same hereditary calling; clinging to the same customs, especially regarding purity, meals, and marriages; and often further divided into smaller endogamous circles. Caste is a group of people having a specific social rank, defined generally by descent, marriage, commensality and occupation. Although the term 'caste' is applied to hierarchically ranked groups of people in many different societies around the world, the caste system in its most developed form is found in Indian subcontinent.

The English word "caste" derives from the Spanish and Portuguese casta, which means, "race, lineage, or breed" (Mookherjee, 2012: 56). When the Spanish colonized the New World, they used the word to mean a "clan or lineage." However, the Portuguese were the ones who employed casta in the primary modern sense when they applied it to the many in-marrying hereditary Hindu social groups they encountered upon their arrival in India in 1498.

One of the problems with any understanding of caste is that the word "caste" itself has been used to translate two quite different Sanskrit concepts which are assumed, quite wrongly, to have an automatic connection. One is the concept of $j$ ā $i$ and its sense of "kind" or "species". Another way of glossing this concept might be to say "the group that one was born into", the relativity of this gloss conveying the contextual nature of $j$ āt $i$ ascriptions. When asked to name their $j \bar{a} t i$, people may name their patrilineage, the name of the group of lineages they conventionally marry into, or even the name of what would now be called an ethnic group. However, even though the concept is elastic, the idea of origin by birth is constant. There is no mystery about this ( Quigley, 1993: 502).

Scholars approaching caste through the study of Hinduism and comparative religion may be less acquainted with sociological and anthropological studies of caste on the ground and are more likely to be familiar with the Vedic concept of varna which is also used to translate the word "caste". The referent of this concept is rather different from that of $j \mathrm{a} t i$ since the fundamental idea is less "belonging to a group 